\title{
Functional regulation of Zfp36l1 and Zfp36l2 in response to lipopolysaccharide in mouse RAW264.7 macrophages
}

\author{
Kuan-Ting Wang ${ }^{1}$, Hsin-Hui Wang ${ }^{2,3}$, Yan-Yun Wu' ${ }^{1}$ Yu-Lun Su${ }^{1}$, Pei-Yu Chiang ${ }^{1}$, Nien-Yi Lin ${ }^{4}$, Shun-Chang Wang ${ }^{4}$,
} Geen-Dong Chang ${ }^{1}$ and Ching-Jin Chang ${ }^{1,4^{*}}$

\begin{abstract}
Background: The tristetraprolin (TTP) family of mRNA-binding proteins contains three major members, Ttp, Zfp36l1, and Zfp36|2. Ttp down-regulates the stability of AU-rich element-containing mRNAs and functions as an anti-inflammation regulator.

Methods: To examine whether other TTP family proteins also play roles in the inflammatory response, their expression profiles and the possible mRNA targets were determined in the knockdown cells.

Results: Ttp mRNA and protein were highly induced by lipopolysaccharide (LPS), whereas Zfp36/1 and Zfp36/2 mRNAs were down-regulated and their proteins were phosphorylated during early lipopolysaccharide stimulation. Biochemical and functional analyses exhibited that the decrease of Zfp36/2 mRNA was cross-regulated by Ttp. Knockdown of Zfp36l1 and Zfp36/2 increased the basal level of Mkp-1 mRNAs by prolonging its half-life. Increasing the expression of Mkp-1 inhibited the activation of p38 MAPK under lipopolysaccharide stimulation and down-regulated Tnfa, and Ttp mRNA. In addition, hyper-phosphorylation of Zfp36l1 might stabilize Mkp-1 expression by forming a complex with the adapter protein 14-3-3 and decreasing the interaction with deadenylase Caf1a.

Conclusions: Our findings imply that the expression and phosphorylation of Zfp36/1 and Zfp36/2 may modulate the basal level of Mkp-1 mRNA to control p38 MAPK activity during lipopolysaccharide stimulation, which would affect the inflammatory mediators production. Zfp36/1 and Zfp36/2 are important regulators of the innate immune response.
\end{abstract}

Keywords: Tristetraprolin, Zfp3611, Zfp3612, Mkp-1, p38 MAPK, Macrophage

\section{Background}

Activated macrophages produce the classical proinflammatory cytokines to initiate and maintain inflammation. The activities of mitogen-activated protein kinases (MAPKs) including ERK, JNK, and p38 are necessary for initiation of the innate immune response [1]. Both the activation of transcription factors by phosphorylation and the stabilization of AU-rich element (ARE)-containing mRNAs can help cells produce proinflammatory mediators or cytokines [2-4]. Some negative regulators such as MAPK phosphatase-1 (Mkp-1,

\footnotetext{
* Correspondence: chingjin@gate.sinica.edu.tw

'Graduate Institute of Biochemical Sciences, College of Life Science, National Taiwan University, No.1 Sec. 4 Roosevelt Road, Taipei 10617, Taiwan

${ }^{4}$ Institute of Biological Chemistry, Academia Sinica, No.128, Sec.2, Academia

Road, Nankang, Taipei 11529, Taiwan

Full list of author information is available at the end of the article
}

also named Dusp1, dual specific phosphatase 1) and tristetraprolin (Ttp) can help cells return to the resting state $[5,6]$. MAPKs are inactivated by Mkp-1 through dephosphorylation [7]. Mkp-1-deficient mice are highly susceptible to endotoxic shock, which is associated with enhanced production of serum cytokines and chemokines [8-11]. In Ttp-knockout mice, many inflammation syndromes such as dermatitis, cachexia, spontaneous arthritis, and neutrophilia are observed [12] because of overproduction of the pro-inflammatory cytokine tumor necrosis factor- $\alpha$ (Tnf $\alpha)$ through its prolonged mRNA half-life [13]. Ttp (also called TIS11, NUP475, Zfp-36, and G0S24) specifically binds to the ARE in the 3'UTR of Tnfo mRNA. The ARE is a cis-acting RNA element that is usually located in the 3'UTR of short-lived mRNAs encoded by many inflammation- and cancer- 
associated genes [6]. TTP recognizes the ARE via its tandem zinc finger domain, which contains two CysCys-Cys-His $(\mathrm{C} 3 \mathrm{H})$ zinc-binding motifs, and causes its target mRNA to be deadenylated and rapidly degraded [14-16].

The other TTP family proteins are Zfp3611 (also called TIS11b, cMG1, BRF1, ERF1, or Berg36) [17], Zfp36l2 (also called TIS11d, ERF2, or BRF2) [18] and Zfp36l3 [19]. These members contain conserved tandem zinc finger domains that show the same ability as Ttp to destabilize ARE-containing mRNAs $[15,20]$. Their RNA expression levels vary among human tissues [21]. Zfp36l1-deficient mice develop failure of chorioallantoic fusion, and embryos die in utero [22]. Female mice containing a deletion of the first exon of $Z f p 36 l 2$ are completely infertile [23]. Zfp36l2-knockout mice exhibit a defect in hematopoiesis [24]. Zfp36l3 is rodent-specific [19]; it is only expressed in the placenta and extraembryonic tissues of mice.

Ttp mRNA and protein are induced by lipopolysaccharide (LPS) [25]; however, Zfp3611 and Zfp36l2 proteins have not been adequately characterized in LPS-stimulated macrophages. To explore the functional roles of Zfp36l1 and Zfp36l2 in inflammatory response, we examined their expression profiles and knocked down either Zfp36l1 or Zfp36l2 to find their possible mRNA targets in mouse RAW264.7 cells. We observed that Zfp3611 and Zfp3612 would modulate $M k p-1$ mRNA expression in resting macrophages, which inhibited p38 activation and Tnfo induction in response to LPS.

\section{Methods}

\section{Plasmid constructs}

The Flag-tagged mouse Ttp, Zfp3611, and Zfp36l2 expression plasmids, the construct encoding the GST fusion with

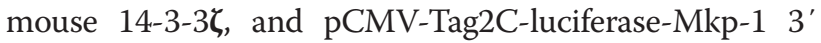
UTR were constructed as described [26]. The sequence of putative AREs of MKP-1 3'UTR was indicated previously [27]. T7 promoter containing Zfp36l1 and Zfp36l2 partial 3'UTR were PCR cloning by using primers, 5'TAATACGACTCACTATAGGGGTTGCTTATCACTGC ACATC-3' and 5'-AAACTGCAAATAGTCGTTAC-3' for Zfp3611, 5'-TAATACGACTCACTATAGGGCACCACTG CACCACAACTC-3' and 5'-AAGCATGGTTTCTTCAT GCG-3' for Zfp36l2. After sequences confirmed, these two fragments were cloned into 3' of luciferase gene in pCMVTag2C-luciferase plasmid (Stratagene, La Jolla, CA).

\section{Cell culture}

RAW264.7 cells were grown in Dulbecco's modified Eagle medium (Gibco, Grand Island, NY) containing $1.5 \mathrm{~g} \cdot \mathrm{L}^{-1}$ sodium bicarbonate and supplemented with $10 \%$ fetal bovine serum (HyClone, Logan, UT) and $2 \mathrm{mM}$ l-glutamine (Gibco). HEK293T cells were grown in Dulbecco's modified Eagle medium (Gibco) containing $3.7 \mathrm{~g} \cdot \mathrm{L}^{-1}$ sodium bicarbonate and supplemented with $10 \%$ fetal bovine serum (Gibco). $100 \mathrm{ng} \cdot \mathrm{mL}^{-1}$ LPS and $20 \mu \mathrm{M}$ of BAY117082 were used (Sigma-Aldrich, St Louis, MO). Both RAW264.7 and HEK293T cells were cultured at $37^{\circ} \mathrm{C}$ in a humidified incubator with $5 \% \mathrm{CO}_{2}$.

\section{Preparation of whole-cell extracts and cytoplasmic/nu- clear extracts}

Confluent RAW264.7 cells in a 10-cm dish were washed once with phosphate-buffered saline (PBS) and then harvested. To prepare whole-cell extracts, the harvested cells $\left(5 \times 10^{6}\right)$ were lysed in $400 \mu \mathrm{L}$ of whole-cell extract buffer (25 mM HEPES pH 7.7, $1.5 \mathrm{mM} \mathrm{MgCl}_{2}, 0.2 \mathrm{mM}$ EDTA, $0.5 \mathrm{mM}$ dithiothreitol (DTT), $0.1 \% \mathrm{v} / \mathrm{v}$ NP-40, $0.3 \mathrm{M}$ $\mathrm{NaCl}$, protease inhibitor cocktail (Sigma-Aldrich) and phosphatase inhibitor containing $0.01 \mathrm{M} \beta$-glycerol phosphate, $0.1 \mathrm{mM} \mathrm{Na}_{2} \mathrm{MoO}_{4}, 0.1 \mathrm{mM} \mathrm{Na}_{3} \mathrm{VO}_{4} \mathrm{pH}$ 10, $0.01 \mathrm{M}$ $\mathrm{NaF}$ ). The cell lysates were shaken at $4{ }^{\circ} \mathrm{C}$ for $30 \mathrm{~min}$ and then centrifuged for $5 \mathrm{~min}$ at $13,000 \mathrm{rpm}, 4{ }^{\circ} \mathrm{C}$. The supernatant was collected as a whole-cell extract. To prepare cytoplasmic and nuclear extracts, harvested cells were lysed in $400 \mu \mathrm{L}$ hypotonic buffer (10 mM HEPES pH 7.5, $10 \mathrm{mM}$ potassium acetate, $2.5 \mathrm{mM}$ DTT, $0.05 \% \mathrm{NP}-40$, protease inhibitor, and phosphatase inhibitor). The cell lysates were shaken at $4{ }^{\circ} \mathrm{C}$ for $30 \mathrm{~min}$ and then centrifuged for $30 \mathrm{~s}$ at $9000 \mathrm{rpm}, 4{ }^{\circ} \mathrm{C}$. Each supernatant was collected as a cytosolic extract, and each nuclear pellet was washed once with hypotonic buffer and then resuspended in $50 \mu \mathrm{L}$ of buffer C (20 mM HEPES pH 7.9, $400 \mathrm{mM} \mathrm{NaCl}$, 1 mM EDTA, 1 mM EGTA, 1 mM DTT, protease inhibitor, and phosphatase inhibitor). The nuclear suspension was shaken at $4{ }^{\circ} \mathrm{C}$ for $30 \mathrm{~min}$ and then centrifuged for $5 \mathrm{~min}$ at $13,000 \mathrm{rpm}, 4{ }^{\circ} \mathrm{C}$. Each supernatant was collected as a nuclear extract. For phosphatase treatment, $100 \mu \mathrm{g}$ of cytoplasmic extract was incubated with $1 \mu \mathrm{L}$ of calf intestinal phosphatase (New England Biolabs, Ipswich, MA) at $37^{\circ} \mathrm{C}$ for $30 \mathrm{~min}$.

\section{Western blot analysis and antibodies}

Four fold of SDS-PAGE sample buffer $(200 \mathrm{mM}$ Tris $\mathrm{pH}$ 6.8, 8 \% SDS, 0.4 \% bromophenol blue, 40 \% glycerol, $400 \mathrm{mM} \beta$-mercaptoethanol) was added to the sample to a final concentration of 1 fold and then heated at $100{ }^{\circ} \mathrm{C}$ for $5 \mathrm{~min}$. Proteins were separated on $10 \%$ polyacrylamide gels and transferred onto a $0.45 \mu \mathrm{m}$-pore-size polyvinylidene difluoride membrane (Millipore, Billerica, MA) for western blotting. The membrane was incubated for $1 \mathrm{~h}$ at room temperature with an antibody against any of the following proteins: BRF1/2, phosphorylated p38 (p-p38) MAPK T180/Y182, p-p44/42 MAPK (all from Cell Signaling), hnRNPC1/C2, MKP-1, ERK1, JNK1 (all from Santa Cruz Biotechnology), total-p38, p-JNK, Flag M2 (all from Sigma-Aldrich), Ttp, Zfp36l1, Zfp36l2, and $\beta$-tubulin [26]. After washing with PBST (PBS containing $0.1 \%$ (v/v) 
Tween 20) for an appropriate time, the membrane was incubated for $1 \mathrm{~h}$ at room temperature with a horseradish peroxidase-conjugated secondary antibody: goat antirabbit IgG (KPL, Gaithersburg, ML), goat anti-mouse IgG (KPL), or rabbit anti-goat (Sigma-Aldrich). Western Lightning enhanced chemiluminescence substrate (Perkin Elmer, Norwalk, CT) was used for detection.

\section{RNA extraction, reverse transcription and real-time PCR}

Total RNA was isolated with TRIzol reagent (Invitrogen, Carlsbad, CA) according to the manufacturer's suggestions. Cells $\left(1 \times 10^{6}\right)$ in a six-well plastic culture plate were washed once with PBS and directly lysed in a well with $1 \mathrm{~mL}$ TRIzol. RNA was used for reverse transcription as described [26]. RNA was quantified with the Applied Biosystems 7300 Real-Time PCR system (Applied Biosystems, Foster City, CA) in a volume of $20 \mu \mathrm{L}$, containing $10 \mu \mathrm{L}$ FastStart Universal SYBR Green Master (Roche, Mannheim, Germany), $4 \mu \mathrm{L}$ of 10 -fold diluted cDNA, $5.6 \mu \mathrm{L}$ diethylpyrocarbonate-treated $\mathrm{H}_{2} \mathrm{O}$, and $0.4 \mu \mathrm{L}$ of 5$20 \mu \mathrm{M}$ forward and reverse primer: $5^{\prime}$-TAGACTCCAT CAAGGATGCTGG-3' and 5'-GCAGCTTGGAGAGG 'TGGTGAT-3' for $M k p-1 ;$ 5'-GACCCTCACACTCA GATCATCTTCT-3' and 5'-CCTCCACTTGGTGGTTT GCT-3' for Tnfo; 5'-GGATCTCTCTGCCATCTACGA$3^{\prime}$ and $5^{\prime}$-CAGTCAGGCGAGAGGTGAC-3' for Ttp; 5' CTGAAGACCTTAGGGCAGAT-3' and $5^{\prime}$-AAGGAA TGGGTCCAGACATAC-3' for Ccl2; 5'-TGTCAGC CACTGCCTTGGTA- $3^{\prime}$ and $5^{\prime}$-CAGGATCTGGTCCG CTAGCT-3' for Icam 1; 5'-TGAGCGAAGTTTTATG CAAGGG-3' and 5'-GCTGGGCAGAGTGACCGAG-3' for Zfp36l1, 5'-GATGTCGACTTGTTGTGCAAGACG-3' and 5'-GCGTCCCTACCGCCTTCT-3' for Zfp36l2, 5'TCCTTCCTGGGCATGGAGTC-3' and ' 5'-ACTCAT CATACTCCTGCTTG-3' for $\beta$-actin. The data were normalized with $\beta$-actin according to the $2^{-\Delta \Delta C t}$ relative quantitation method in the manufacturer's manual.

\section{RNA pull-down assay}

Cytoplasmic extracts from LPS-stimulated RAW264.7 cells were collected as described above. Potassium acetate was adjusted to $90 \mathrm{mM}$, and $0.1 \mathrm{U} \cdot \mu \mathrm{L}^{-1}$ RNasin (Promega, Madison, WI) and $20 \mu \mathrm{g} \cdot \mu^{-1}$ yeast tRNA were added to each lysate. To prevent non-specific binding, heparin-agarose (Sigma-Aldrich) was incubated with each lysate for $15 \mathrm{~min}$ at $4{ }^{\circ} \mathrm{C}$ and then centrifuged for $1 \mathrm{~min}$ at $8000 \mathrm{rpm}, 4^{\circ} \mathrm{C}$. Each supernatant was further cleaned with streptavidin-Sepharose ( $8 \mu \mathrm{L}$; Invitrogen) for $1 \mathrm{~h}$ at $4{ }^{\circ} \mathrm{C}$ and then centrifuged for $1 \mathrm{~min}$ at $8000 \mathrm{rpm}, 4{ }^{\circ} \mathrm{C}$. Mkp-1 3'UTR cloned in T7 promoter-containing plasmid or T7 promoter-containing Zfp36l1 3'UTR or Zfp36l2 3'UTR DNA fragment was used as a template and transcribed into RNA in the presence of biotin-CTP by using the T7-MEGA shortscript, High Yield Transcription kit
(Ambion, Grand Island, NY) and then incubated with above supernatants for $1 \mathrm{~h}$ at $4{ }^{\circ} \mathrm{C}$. Biotin-labeled $18 \mathrm{~S}$ RNA was a negative control. Next, streptavidin-Sepharose $(8 \mu \mathrm{L})$ was added to the pulled-down biotinylated RNA complex for $2 \mathrm{~h}$ at $4{ }^{\circ} \mathrm{C}$. The pulled-down complexes were washed four times with binding buffer (hypotonic buffer containing $90 \mathrm{mM}$ potassium acetate). Finally, the RNA complexes were separated by SDS-PAGE (10\% acrylamide) and detected by western blotting.

\section{Dual luciferase reporter assay}

HEK293T cells were seeded in a six-well plastic culture plate and transfected using calcium phosphate precipitation with different plasmids (containing $0.25 \mu \mathrm{g}$ Renilla luciferase expression vector as a control of transfection rate) at $30 \%$ confluency. At $24 \mathrm{~h}$ post-transfection, the cells $\left(5 \times 10^{5}\right)$ were harvested and lysed in $50 \mu \mathrm{L}$ of passive lysis buffer (Promega). The samples were shaken for $30 \mathrm{~min}$ at $4{ }^{\circ} \mathrm{C}$ and centrifuged for $5 \mathrm{~min}$ at $13,000 \mathrm{rpm}, 4{ }^{\circ} \mathrm{C}$. The supernatants were collected for Dual-Luciferase reporter assay (Promega). The firefly luciferase activity was normalized with the Renilla luciferase activity. All the experiments were carried out in duplicate and repeated for three times.

\section{Lentivirus knockdown}

Lentivirus vectors encoding shRNA targeted to mouse Zfp36l1, Zfp36l2, and control Luciferase were purchased from the National RNAi core facility (Academia Sinica) and used in knockdown studies as described [26]. HEK293T cells $\left(1 \times 10^{6}\right)$ were seeded in a 10 -cm dish for transfection (calcium phosphate precipitation method) of virus production vectors, $14 \mu \mathrm{g}$ of CMV $\Delta$ R8.9.1, $2 \mu \mathrm{g}$ of pMD.G, and $14 \mu \mathrm{g}$ of specific shRNA sequence-bearing pLKO.1 plasmids. At $8 \mathrm{~h}$ post-transfection, the culture medium was replaced with fresh medium for RAW264.7 cells. Viruscontaining medium was collected 24 and $48 \mathrm{~h}$ later for primary-infection and super-infection of RAW264.7 cells. Virus-containing medium was replaced with fresh medium for RAW264.7 cells $24 \mathrm{~h}$ after super-infection. To generate stable knockdown clones, puromycin $\left(3 \mu \mathrm{g} \cdot \mathrm{mL}^{-1}\right)$ was added and Green fluorescent protein signal served as a selection marker. After puromycin selection for one week, cells were harvested and analyzed by western blotting to determine knockdown efficiency.

\section{GST fusion protein production and GST pull-down assay}

Glutathione-Sepharose 4B beads (approximately $8 \mu \mathrm{l}$, GE Healthcare, Piscatway, NJ) were incubated with bacterially expressed GST or GST-14-3-3 proteins in PBS containing $1 \%(\mathrm{v} / \mathrm{v})$ Triton X-100 on a rotary shaker for $20 \mathrm{~min}$ at room temperature. After washing three times with the same buffer, the beads were combined with $500 \mu \mathrm{g}$ of each cell lysate from LPS-stimulated RAW264.7 cells in a final 
volume of $200 \mu \mathrm{l}$ of buffer containing $20 \mathrm{mM}$ HEPES, $\mathrm{pH}$ 7.9, $100 \mathrm{mM} \mathrm{NaCl}, 2.5 \mathrm{mM} \mathrm{MgCl}, 0.1 \mathrm{mM}$ EDTA, $0.05 \% \mathrm{NP}-40$, and $1 \%$ Triton X-100, along with $1 \mathrm{mM}$ DTT, and $1 \mathrm{mM}$ phenylmethylsulfonyl fluoride, on a rotary shaker. The mixtures were incubated at $4{ }^{\circ} \mathrm{C}$ for $2 \mathrm{~h}$, and then the beads were washed four times with the same buffer lacking DTT and phenylmethylsulfonyl fluoride but containing $200 \mathrm{mM} \mathrm{NaCl}$ and washed once with $50 \mathrm{mM}$ Tris, $\mathrm{pH}$ 6.8. Bound proteins were eluted by boiling in SDSPAGE sample buffer and analyzed by immunoblotting.

\section{Statistical analysis}

All of the results are presented as the mean \pm SD of at least three independent experiments. The statistically significant values were calculated by one-tailed Student's $t$-test. One asterisk indicates $P$-value $<0.05$, and two asterisks indicate $P$-value $<0.01$. ns indicates non-significance.

\section{Results}

Constitutive expression and phosphorylation of Zfp36l1 and Zfp36I2 during early LPS stimulation in RAW264.7 cells

Ttp plays a key role in the innate immune response. Ttp mRNA and protein were highly induced by LPS (Fig. 1a, b). To investigate the roles of two other TTP family proteins, Zfp36l1 and Zfp3612, in the inflammatory response, we first examined their RNA and protein expression profiles in LPS-stimulated RAW264.7 cells. Zfp3611 and Zfp36l2 proteins were near consistently maintained in the cytoplasm during early LPS stimulation (Fig. 1a) although their RNA expression levels decreased (Fig. 1b). Multiple forms of Zfp3611 and Zfp36l2 were detected by western blotting, and LPS treatment resulted in a shift in their bands (Fig. 1a). When cytoplasmic extracts from 120-min LPS-stimulated cells were treated with calf intestinal phosphatase for $30 \mathrm{~min}$, the higher-migrating protein bands of Zfp3611 and Zfp36l2 shifted back to their lower positions (Fig. 1c). These observations suggested that Zfp36l1 and Zfp36l2 proteins were maintained at a constant level and were phosphorylated under LPS stimulation. They might play functions in resting state and their activity might be regulated by protein phosphorylation.

\section{Down-regulation of Zfp36/1 and Zfp36/2 mRNA by Ttp during LPS-stimulation}

We are interested in the molecular mechanism of downregulation of Zfp36l1 and Zfp36l2 mRNA in response to LPS treatment. Their mRNA 3'UTR contains potential AREs (Additional file 1: Figure S1), we examined whether their mRNA half-life was regulated by LPS. As shown in Fig. 2a, the half-life of Zfp36l1 mRNA was longer than that of Zfp36l2 mRNA, which was $5.2 \mathrm{~h}$ for Zfp36l1 and 39 min for Zfp $36 l 2$. The half-life of Zfp36l2 mRNA was significantly shortened to $13 \mathrm{~min}$ at $20 \mathrm{~min}$ of LPS treatment, and then restored to $33 \mathrm{~min}$ at $50 \mathrm{~min}$ treatment. Although the half-lives of Zfp3611 mRNA were also decreased upon LPS treatment, they still maintained to near $4 \mathrm{~h}$ (Fig. 2a). It was known that Ttp induced by LPS can destabilize ARE-containing mRNA [13, 25]. We have demonstrated that NF-kB signaling pathway was required for Ttp induction [28]. To examine whether Ttp expression plays roles in the down-regulation of $Z f p 36 l 1$ and $Z f p 36 l 2 \mathrm{mRNA}$, we compared the mRNA expression of Ttp, Zfp36lland Zfp36l2 in the presence of the inhibitor (BAY) of NF-kB pathway. The pretreatment with BAY inhibited the mRNA level of Ttp in LPS-stimulation for $0.5 \mathrm{~h}$ and $2 \mathrm{~h}$, which was consistent with the increases of Zfp36l2 mRNA level (Fig. 2b), but no correlation with the levels of Zfp36l1 mRNA. The increase of Zfp36l2 mRNA under BAY treatment was due to the increase of mRNA half-life, whereas BAY treatment would shorten Zfp36l1 mRNA half-life (Fig. 2c). Moreover, the biotin-labeled partial 3'UTR from Zfp36l1 or Zfp36l2 associates with Ttp proteins in RNA pull-down analysis (Fig. 2d), and the 3'UTR-mediated luciferase activity was down-regulated when cotransfection with Ttp expression vector (Fig. 2e). Although both Zfp36l1 and Zfp36l2 3'UTR showed physical and functional interaction with ectopic expressive Ttp, only endogenous Zfp36l2 mRNA was decreased by LPSinduced NF- $\mathrm{kB}$ signals. The results suggest that in addition to Ttp there are other factors involved in the regulation of Zfp36l1 mRNA stability during LPS stimulation.

\section{Zfp36I1 and Zfp36l2 destabilize Mkp-1 mRNA in resting RAW264.7 cells}

Because Zfp3611 and Zfp36l2 were expressed in control macrophages, we inferred that they play roles in controlling mRNA stability under resting conditions. The strategy to identify the mRNA targets of Zfp36l1 and Zfp36l2 was to knockdown Zfp36l1 and Zfp3612 levels using lentiviruscarrying short hairpin RNAs (shRNAs) in RAW264.7 cells. The knockdown efficiency of shRNA specific to Zfp36l1 and Zfp36l2 was confirmed by western blotting (Fig. 3a). ARE-containing immediate early genes as well as inflammatory mediator genes such as Ttp, Mkp-1, Tnfo, Ccl-2, and Icam-1 were candidate targets of Zfp3611 and Zfp36l2 [29, 30]. Expression of these candidate RNAs was examined by real-time PCR in different knockdown cells, including Zfp3611 knockdown, Zfp36l2 knockdown, and Zfp3611/ Zfp36l2 dual-knockdown cells. We predicted that the mRNA targets of Zfp3611 and Zfp3612 would increase in knockdown cells because Zfp3611 and Zfp36l2 function in mRNA destabilization. We found that $M k p-1$ mRNA was significantly increased in all knockdown cells (Fig. 3b). We determined the half-life of $M k p-1$ mRNA in the different knockdown cell types; the half-life increased from $19 \mathrm{~min}$ in control cells to near 100 min in knockdown cell types 

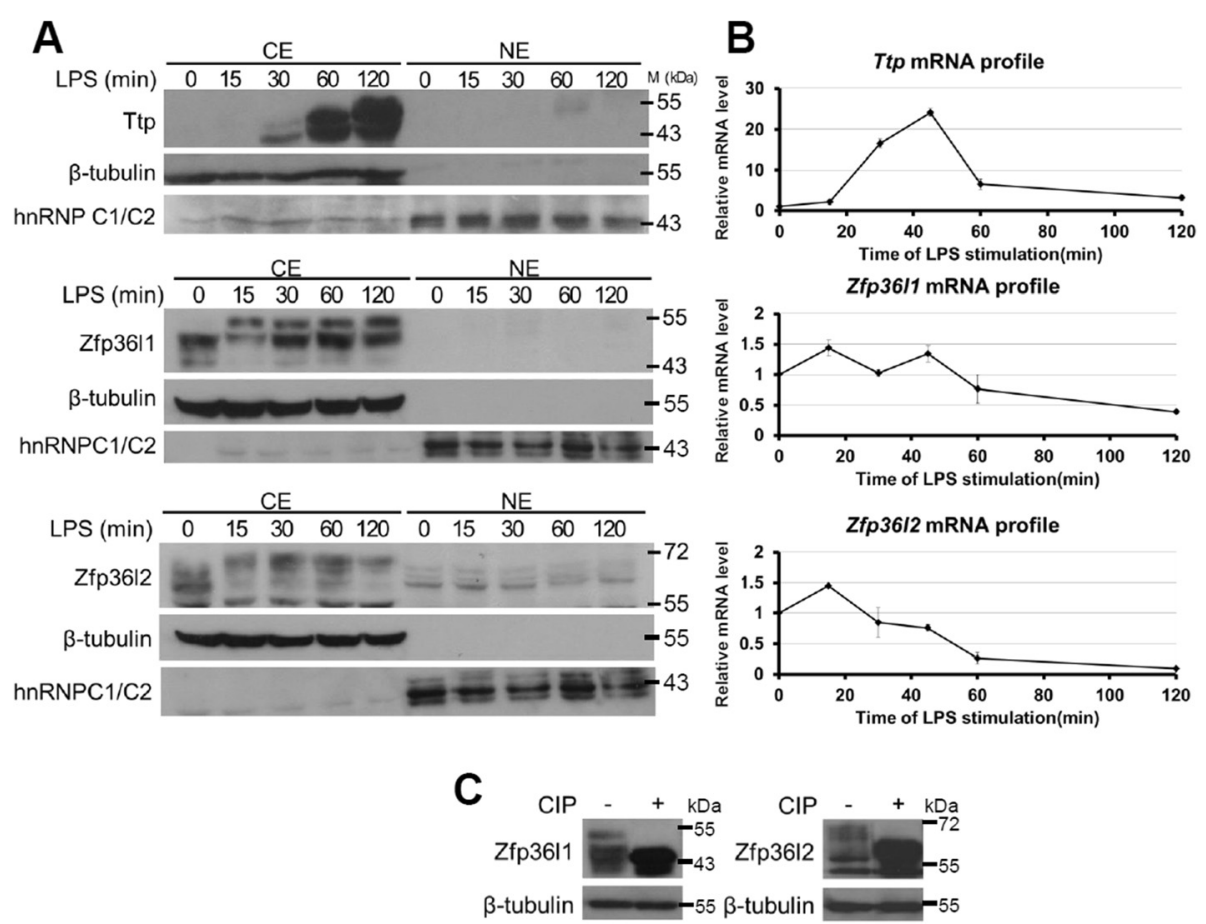

Fig. 1 Consistent expression and phosphorylation of Zfp36l1 and Zfp36l2 during LPS stimulation in RAW264.7 cells. a Protein expression profiles of TTP family members in RAW264.7 cells stimulated with LPS for 0, 15, 30, 60, or 120 min. Cytoplasmic extracts (CE) and nuclear extracts (NE) were isolated for western blotting analysis using the indicated antibodies. $\beta$-tubulin was a loading control for the cytoplasmic extract, and hnRNPC1/C2 was a loading control for the nuclear extract. Positions of molecular size markers $(M)$ are shown to the right. The blots were performed at least three times, and representative results from replicate experiments were presented. $\mathbf{b}$ mRNA expression profiles of TTP family members in RAW264.7 cells stimulated with LPS for $0,15,30,60$, or 120 min. RNA was isolated for quantitative PCR analysis to measure Ttp, Zfp36/1, Zfp36/2 mRNA levels. The relative mRNA level was shown as mean \pm SD of three independent samples normalized to $\beta$-actin mRNA level. c Cytosolic extracts from RAW264.7 cells stimulated with LPS for 120 min were treated with calf intestinal phosphatase for $30 \mathrm{~min}$ and then were subjected to SDS-PAGE for western blotting analysis

(Fig. 3c). In contrast, Ttp, Tnfa, Ccl-2, and Icam-1 mRNA levels were decreased in the knockdown cells or slightly increased but no significance (Fig. 3d). These results suggested that both Zfp36l1 and Zfp36l2 down-regulate Mkp1 mRNA stability in resting macrophages but enhance the mRNA expression of Tnfo and Ccl-2.

\section{Zfp36l1 and Zfp36l2 interact with the Mkp-1 3'UTR and recruit the deadenylase Caf1a in RAW264.7 cells}

We further explore the molecular mechanism underlying Zfp3611 and Zfp36l2 regulated $M k p-1$ mRNA stability in resting macrophages. We have demonstrated that TTP family proteins including Ttp, Zfp3611 and Zfp3612 interacted with $M k p-1$ mRNA $3^{\prime} \mathrm{UTR}$ during differentiation of 3 T3-L1 preadipocytes [26, 27], and Mkp-1 3'UTR-derived luciferase activity was reduced when co-transfected with Zfp3611 or Zfp36l2 expression plasmid in human embryonic kidney (HEK293T) cells [26]. The deadenylase CAF1 (Ccr4-associated factor) is recruited by TTP through interacting with NOT1 to destabilize target mRNAs [31-34]. Both Zfp3611 and Zfp36l2 contain NOT1binding domain [35]. A recent report showed that
ZFP36L1 immunoprecipitated CAF1 (also named CNOT7) [36]. To understand how Zfp36l1 and Zfp36l2 regulate $M k p-1$ mRNA stability during LPS stimulation, an RNA pull-down assay was performed to examine the RNA-protein interaction. Biotinylated Mkp-1 3'UTR was incubated with cytosolic lysates from LPS-stimulated RAW264.7 cells. The ribonucleoprotein complexes were precipitated with streptavidin-Sepharose and then subjected to SDS-PAGE for western blotting with antiZfp36l1 and anti-Zfp36l2 (Fig. 4a). The interaction between Zfp36l1 and Mkp-1 3'UTR appeared to be constant during LPS stimulation, whereas the precipitated amount of Zfp3612 byMkp-1 3'UTR was varied from relative level 1 to 0.34 (Fig. 4a). Interestingly, the lowest level of precipitated Cafla by $M k p-13^{\prime}$ UTR was observed in LPS stimulation for $15 \mathrm{~min}$, suggesting that $M k p-1$ mRNA would be stabilized after LPS stimulation.

It has been reported that the interaction between phosphorylated Ser92 and Ser203 of Zfp3611 and the protein 14-3-3 can inhibit the mRNA decay activity of Zfp36l1 after insulin stimulation [37, 38]. Because LPS-induced Zfp3611 phosphorylation did not affect its RNA-binding activity 
A
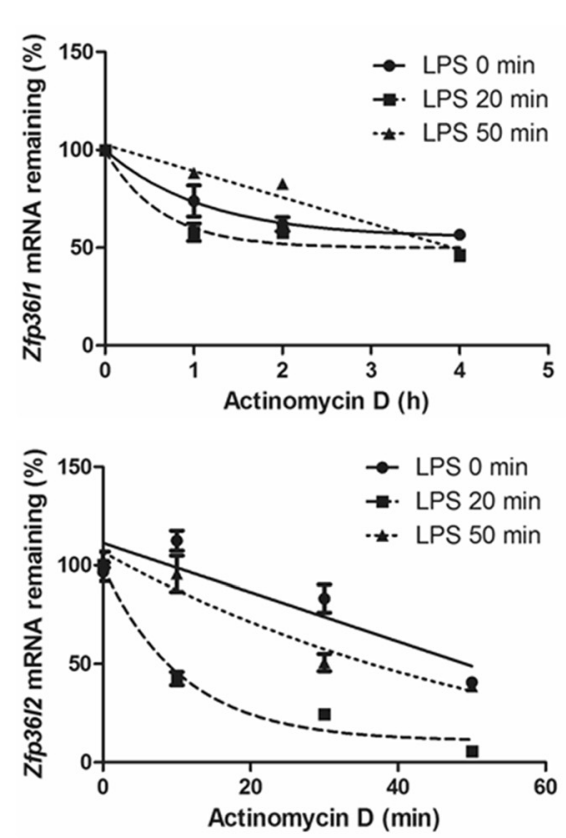

B
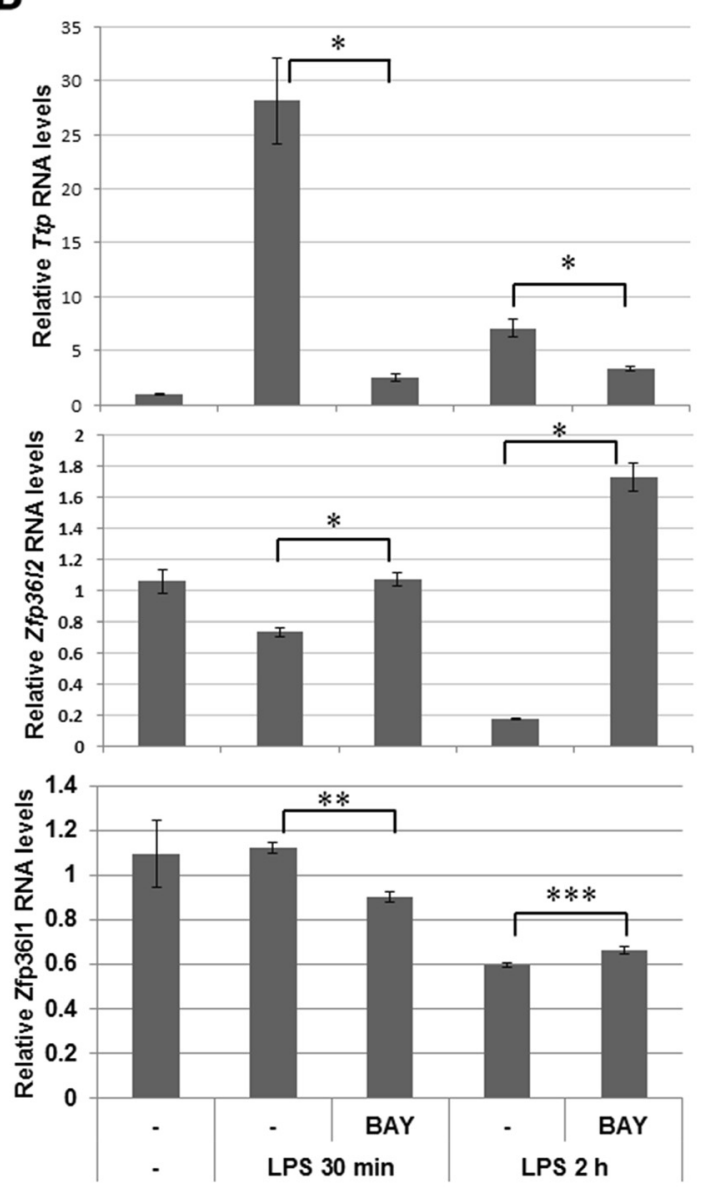

C
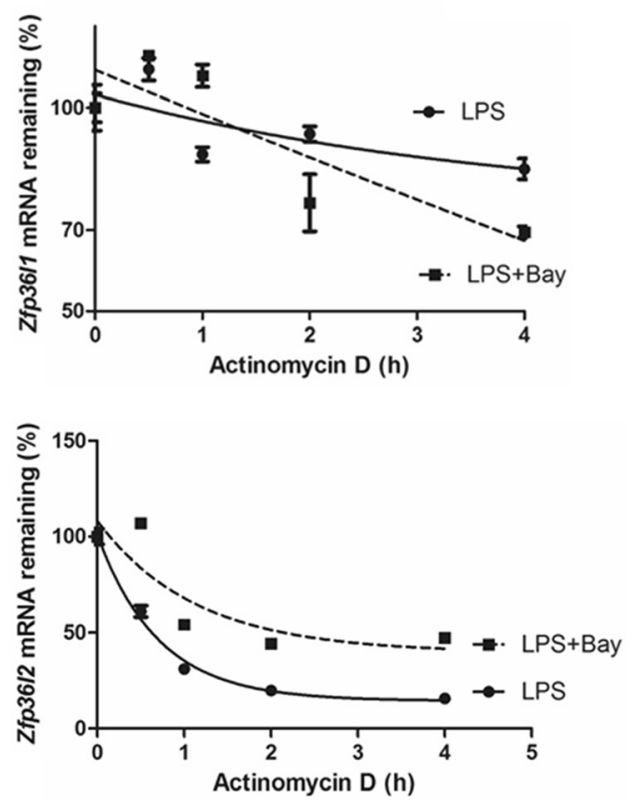

D

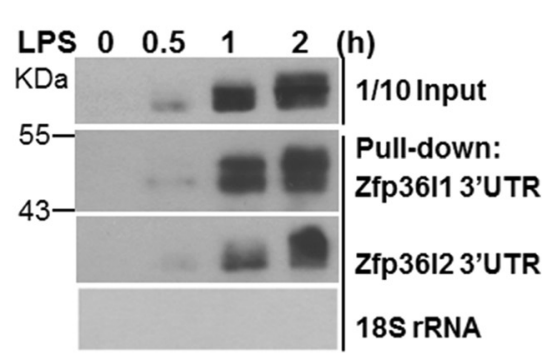

WB: anti-Ttp

E
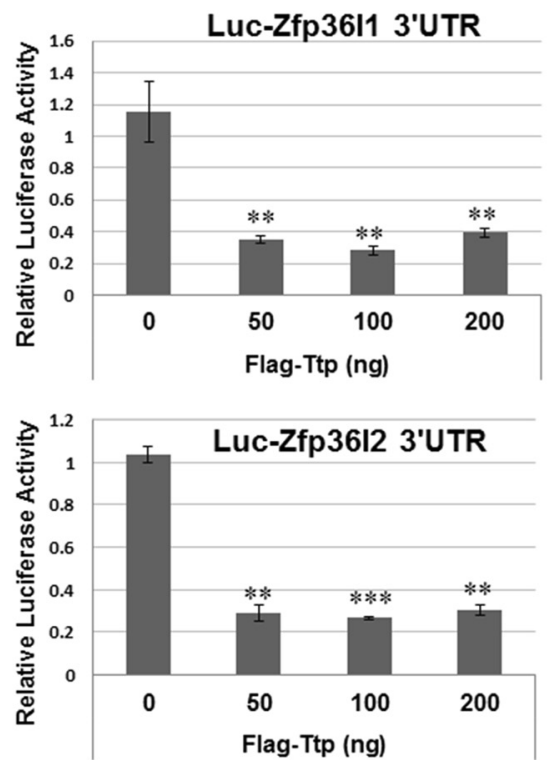

Fig. 2 (See legend on next page.) 
(See figure on previous page.)

Fig. 2 mRNA stability regulation of Zfp36/2 by Ttp during LPS-stimulation. a mRNA half-life determination. RAW264.7 cells stimulated with LPS for 0, 20 and $50 \mathrm{~min}$, and actinomycin D $\left(10 \mu \mathrm{g} \cdot \mathrm{mL}^{-1}\right)$ was added for $0,10,30$, and 50 min to stop transcription for Zfp36/2 mRNA detection, and added for 0 , 1,2 and $4 \mathrm{~h}$ for Zfp36/1 mRNA detection. RNAs was isolated for quantitative PCR by using primers of $\beta$-actin, Zfp36/1 and Zfp36/2. The remaining Zfp36/1 and Zfp3612 mRNA levels were shown after normalized with the level of $\beta$-actin. The mRNA half-lives were calculated by exponential regression: $5.2 \mathrm{~h}$, $4.2 \mathrm{~h}$, and $3.5 \mathrm{~h}$ for Zfp36/1 at 0, 20 min, and 50 min of LPS treatment, respectively; $39 \mathrm{~min}, 13 \mathrm{~min}$ and 33 min for Zfp36/2 at 0,20 min, and 50 min of LPS treatment, respectively. $\mathbf{b}$ TTP family mRNA analysis under BAY treatment. RAW264.7 cells were pretreated with or without $20 \mu \mathrm{M}$ of BAY for $0.5 \mathrm{~h}$ followed by adding $100 \mathrm{ng} \cdot \mathrm{mL}^{-1}$ LPS for 0.5 and $2 \mathrm{~h}$. Total RNAs were isolated for quantitative PCR. c BAY treatment stabilizes Zfp36/2 mRNA. RAW264.7 cells pretreated with or without $20 \mu \mathrm{M}$ of BAY for $0.5 \mathrm{~h}$ followed by adding $100 \mathrm{ng} \cdot \mathrm{mL}^{-1} \mathrm{LPS}$ for $20 \mathrm{~min}$, and actinomycin D was added for $0,0.5,1,2$, and $4 \mathrm{~h}$ to stop transcription. RNAs was isolated for quantitative PCR and Zfp36/1 and Zfp36/2 mRNA half-lives were determined. d RNA pull-down analysis. Biotin labeled Zfp36/1 3'UTR, Zfp36/2 3'UTR and control 18S RNA were incubated with cytosolic extracts from RAW264.7 cells treated with LPS for 0, 0.5, 1 and 2 h, respectively. After extensive washes, the RNA-protein complexes were analyzed by western blotting with anti-Ttp. e Luciferase reporter analysis. 293 T cells were cotransfected with of $0.25 \mu \mathrm{g}$ Zfp36/1 3'UTR- or Zfp36/2 3'UTR-containing luciferase reporter and different amounts of Flag-tagged Ttp expression plasmid. After normalized with internal control of Renilla luciferase activity, the relative firefly luciferase activity was shown. All experiments were independently repeated at least two times

(Fig. 4a), a glutathione-S-transferase (GST) pull-down assay was performed to study whether Zfp36l1 that becomes hyper-phosphorylated during LPS stimulation interacts with 14-3-3. As shown in Fig. 4b, only hyper-phosphorylated Zfp3611 formed a complex with 14-3-3. This complex might repress the mRNA destabilization function of Zfp3611. No prominent Zfp36l2 was detected in this pull- down assay (data not shown). These results suggest that Zfp36l1 and Zfp36l2 bind to $M k p-1$ 3'UTR and may recruit RNA degradation complex in the resting macrophages. During LPS stimulation Zfp3611 would be phosphorylated and sequestrated by $14-3-3$ to decrease its mRNA destabilization effect, and the phosphorylated Zfp36l2 decreased its interaction with $M k p-1$ 3'UTR.
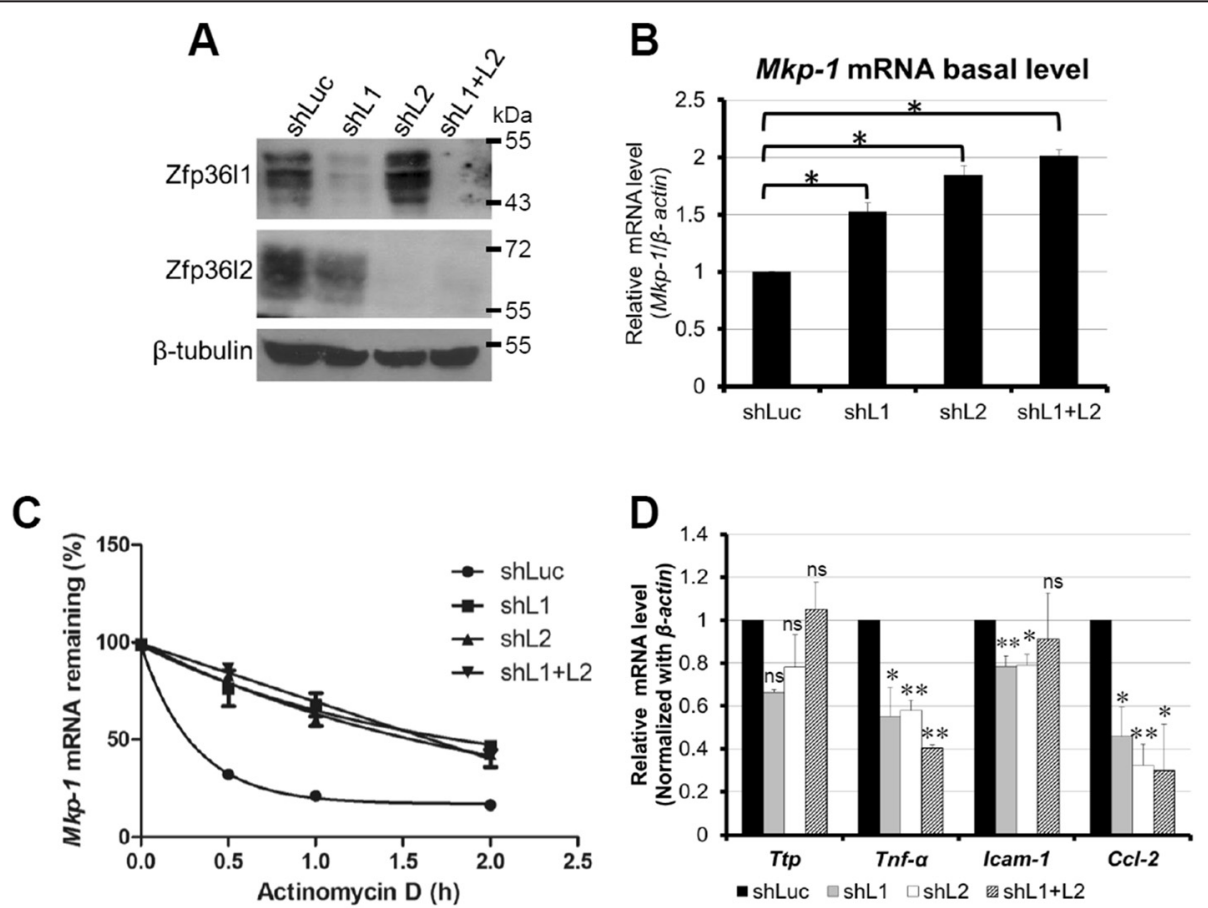

Fig. 3 Zfp36l1 and Zfp36l2 destabilize Mkp-1 mRNA in resting RAW264.7 cells. a shLuc, shL1, shL2, shL1 + L2 represent luciferase knockdown cells, Zfp3611-knockdown cells, Zfp36l2-knockdown cells, and dual Zfp36l1- and Zfp36l2-knockdown cells, respectively. The upper two panels show the knockdown efficiency. $\beta$-tubulin was used as a loading control. Whole-cell extracts were collected for western blotting analysis using the indicated antibodies. $\mathbf{b}$ Basal levels of $M$ kp-1 mRNA were detected by quantitative PCR in different knockdown cells. c Analysis of Mkp-1 mRNA half-life in different knockdown cells. Actinomycin $D\left(10 \mu \mathrm{g} \cdot \mathrm{mL}^{-1}\right)$ was added to stop transcription for $0,0.5,1$ or $2 \mathrm{~h}$. The remaining mRNA was detected by quantitative PCR. Mkp-1 mRNA half-life was calculated by exponential regression, 19 min in control cells and 91,96 and 95 min in Zfp36l1, Zfp36l2 and dual knockdown cells, respectively. d Basal levels of Ttp, Tnfa, Icam-1, and Ccl-2 mRNAs were examined by quantitative PCR in different knockdown cells and normalized to the shLuc control. All of experiments were independently performed at least three times 


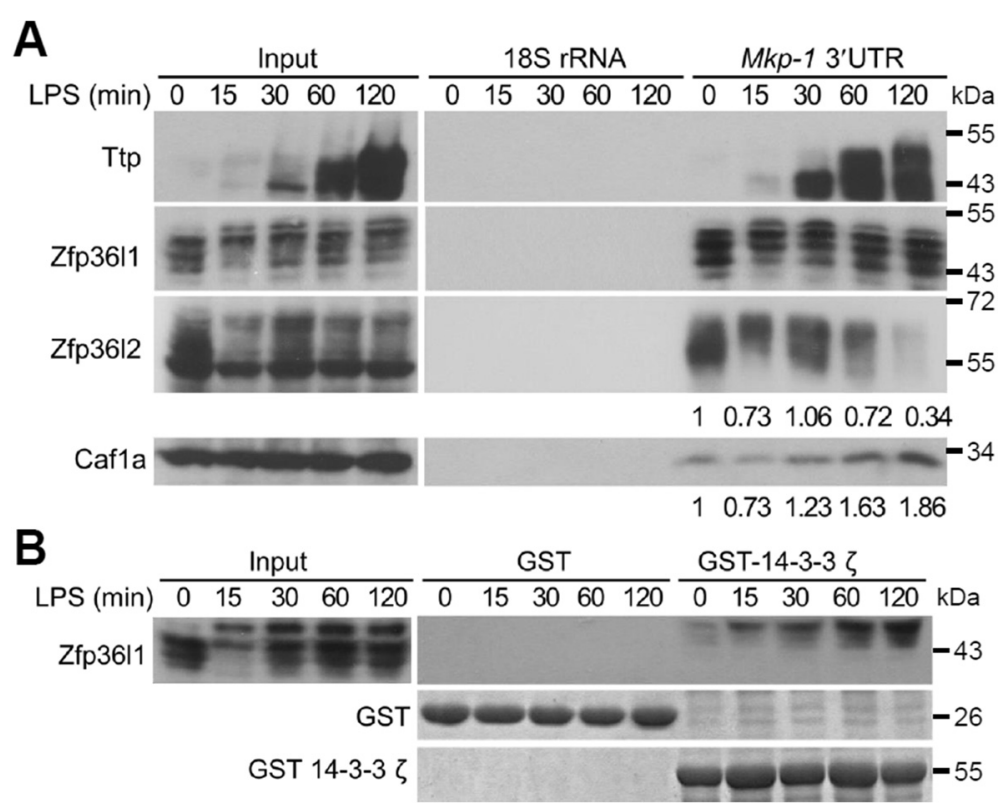

Fig. 4 Zfp36l1 and Zfp36l2 interact with Mkp-1 3'UTR in RAW264.7 cells. a Interaction of TTP family proteins and Mkp-1 mRNA. Biotinylated-Mkp-1 3'UTR fragments were incubated with cytosolic extracts from control RAW264.7 or LPS-treated cells for 15, 30, 60, or 120 min. The biotinylated RNAs and associated proteins were precipitated by streptavidin beads, separated by SDS-PAGE, and analyzed by western blotting with anti-Ttp, anti-Zfp36l1, anti-Zfp36l2, and anti-Caf1a as indicated. Biotinylated 18S rRNA was used as a negative control. The pull-down protein levels were quantified as indicated below the lanes. b Interaction of Zfp36l1 with 14-3-3. E. coli-expressed GST-14-3-3 $\zeta$ or GST was bound on glutathione Sepharose 4B. The beads were incubated with the cell lysates from LPS-stimulated RAW264.7 cells for 0, 15, 30, 60, or 120 min. The pulled-down protein complexes were separated by SDS-PAGE and analyzed by western blotting with anti-Zfp36/1. All of the experiments were performed at least three times, and representative data were displayed

Induction of Mkp-1 mRNA early during LPS stimulation is post-transcriptionally modulated by Zfp36I1 and Zfp36I2

To further investigate the regulation of $M k p-1$ mRNA during early LPS stimulation in RAW264.7 cells, we examined the expression of its mRNA (Fig. 5a). $M k p-1$ mRNA increased significantly after LPS stimulation from 15 to $30 \mathrm{~min}$ but decreased rapidly after $45 \mathrm{~min}$. To verify the functions of Zfp36l1 and Zfp3612 immediately following LPS treatment, we examined the level of $M k p-1$ mRNA in Zfp36l1- and Zfp36l2-knockdown cells after LPS stimulation for $15 \mathrm{~min}$, in this time point Ttp protein was not induced significantly and the lowest level of brought-down Cafla by $M k p-1$ 3'UTR was observed in Fig. 4a. The observed marked rise in the mRNA level in all knockdown cells compared with control knockdown cells implied that the decrease in Zfp36l1 and Zfp36l2 protein expression facilitated the expression of $M k p-1$ mRNA in response to LPS (Fig. 5b); furthermore, the relative $M k p-1$ mRNA half-life at LPS-stimulation $15 \mathrm{~min}$ in control, Zfp36l1, Zfp36l2, and dual-knockdown cells was $32 \mathrm{~min}, 55 \mathrm{~min}$, $68 \mathrm{~min}$, and $42 \mathrm{~min}$, respectively (Fig. 5c). Our results indicate that knockdown of Zfp3611, Zfp36l2, or both proteins also cause the increase of $M k p-1$ mRNA half-life at early LPS stimulation for 15 min like at the resting status. Moreover, $M k p-1$ mRNA at early LPS stimulation in control shLuc cells appeared more stable (half-life is $32 \mathrm{~min}$ ) than which at the resting condition (half-life is $19 \mathrm{~min}$ ) showed in Fig. 3c. It might be due to phosphorylation of Zfp36l1 and Zfp36l2 upon LPS stimulation leading to protein inactivation.

p38 MAPK activity is regulated by Zfp36l1 and Zfp36I2 through Mkp-1 in LPS-stimulated RAW264.7 cells

Because Mkp-1 has been reported to decrease p38 and Jnk activity as an anti-inflammation regulator [39], we further examined the three MAPK activities in Zfp3611and Zfp3612-knockdown cells. Under resting conditions, p38 activity inversely correlated with Mkp-1 expression, but the activities of Erk and Jnk were unchanged (Fig. 6a). Following LPS stimulation, Mkp-1 expression was detected much earlier in knockdown cells than in control cells, and it down-regulated p38 activity (Fig. 6b). Ttp and Tnfo mRNA expression was reduced in all knockdown cells under LPS stimulation, presumably as a result of decreased p38 activity by Mkp-1 (Fig. 6c). We examined the mRNA expression of some of ARE-containing cytokines including $I L-1, I L-6$ and Ccl2 [40]. Their expression was decreased in Zfp36l1 and Zfp36l2 knockdown cells (Additional file 2: Figure S2). Collectively, our results suggest that both Zfp3611 and Zfp36l2 are necessary for the initiation of the innate immune response in macrophages. 

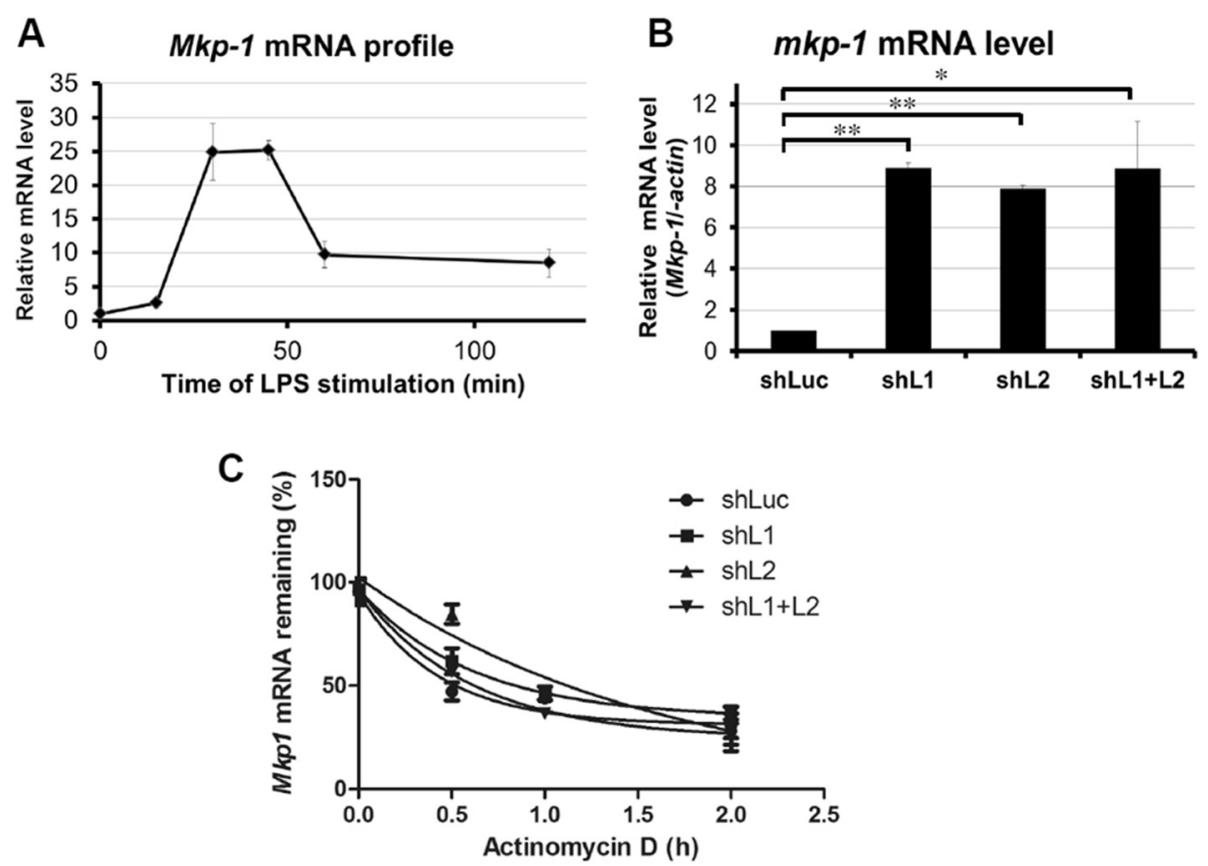

Fig. 5 Induction of Mkp-1 mRNA early during LPS stimulation is post-transcriptionally modulated by Zfp36l1 and Zfp36l2. a mRNA expression profile of Mkp-1 in RAW264.7 cells stimulated with LPS for 0, 15, 30, 45, 60, or 120 min. b Levels of Mkp-1 mRNA in different knockdown cells after LPS stimulation for $15 \mathrm{~min}$. RNA was isolated and performed the real-time PCR analysis. c Analysis of Mkp-1 mRNA half-life in different knockdown cells after LPS stimulation for $15 \mathrm{~min}$. Actinomycin $\mathrm{D}\left(10 \mu \mathrm{g} \cdot \mathrm{mL}^{-1}\right)$ was added to stop transcription after 0 , 10, or 20 min. The remaining mRNA was detected by quantitative PCR. Mkp-1 mRNA half-life was calculated by exponential regression, $32 \mathrm{~min}, 55 \mathrm{~min}, 68 \mathrm{~min}$, and $42 \mathrm{~min}$ in control, Zfp36l1, Zfp36l2, and dual-knockdown cells, respectively. All of experiments were carried out at least three times

\section{Discussion}

Our data show that the levels of Zfp36l1 and Zfp36l2 mRNA decreased during LPS stimulation, and their proteins were consistently expressed and phosphorylated in response to LPS. Knockdown of Zfp3611 and Zfp36l2 increased the expression of Mkp-1, and the activity of p38 MAPK was down-regulated under resting conditions. Thus, p38-mediated expression of Ttp and Tnfo mRNAs was repressed. According to these results, we propose the following model for the mechanism of Zfp3611- and Zfp3612-regulated $M k p-1$ expression in mouse macrophages (Fig. 7). Under a resting condition, Zfp3611 and Zfp36l2 destabilize $M k p-1$ mRNA, and the cells are sensitive to stimuli such as LPS due to low $M k p-1$ expression. During transient LPS stimulation, $M k p-1$ mRNA is induced post-transcriptionally by hyper-phosphorylated Zfp3611, which inhibits mRNA degradation, and by lower interaction with Zfp36l2.

There are two interesting features the expression profiles of endogenous TTP family genes during LPS stimulation in mouse macrophage RAW264.7 cells. One is that the protein expression profiles of these three TTP family members differed, and the second is that the mRNA and protein expression profiles of Zfp3611 and Zfp36l2 were not correlated. Ttp was induced after LPS stimulation, and Zfp3611 and Zfp3612 were consistently expressed. This observation indicates that Zfp3611 and Zfp3612 may play important roles under resting conditions. The mRNA expression profiles of $Z f p 36 l 1$ and $Z f p 36 l 2$ were not correlated with their protein profiles after LPS stimulation (Fig. 1a, b). Similar observations regarding Zfp36l1 and Zfp36l2 mRNA expression profiles were reported by Liang et al. [41] and Cao et al. [42]. We had demonstrated that Zfp36l2 mRNA was negatively regulated by Ttp (Fig. 2). This crossregulation in TTP family proteins was also reported in yeast orthologs, Cth1 and Cth2 [43]. Furthermore, posttranslational modifications such as phosphorylation may alter protein stability $[44,45]$. Zfp3611 and Zfp36l2 may be more stable in the hyper-phosphorylated forms than in the hypo-phosphorylated forms. Thus, their protein expression levels are nearly constant even if their mRNA levels decrease after LPS stimulation. However, a recent report showed that Zfp36l2 protein is also downregulated during LPS treatment [46]. This might be due to a higher dose of LPS and longer stimulation times that were used.

To identify the possible mRNA targets of Zfp3611 and Zfp36l2 in resting macrophages, we knocked down Zfp36l1 and Zfp36l2 using lentivirus-carrying shRNA. Based on previous reports, the candidate mRNA targets are chosen for analysis by the number of AREs in their 

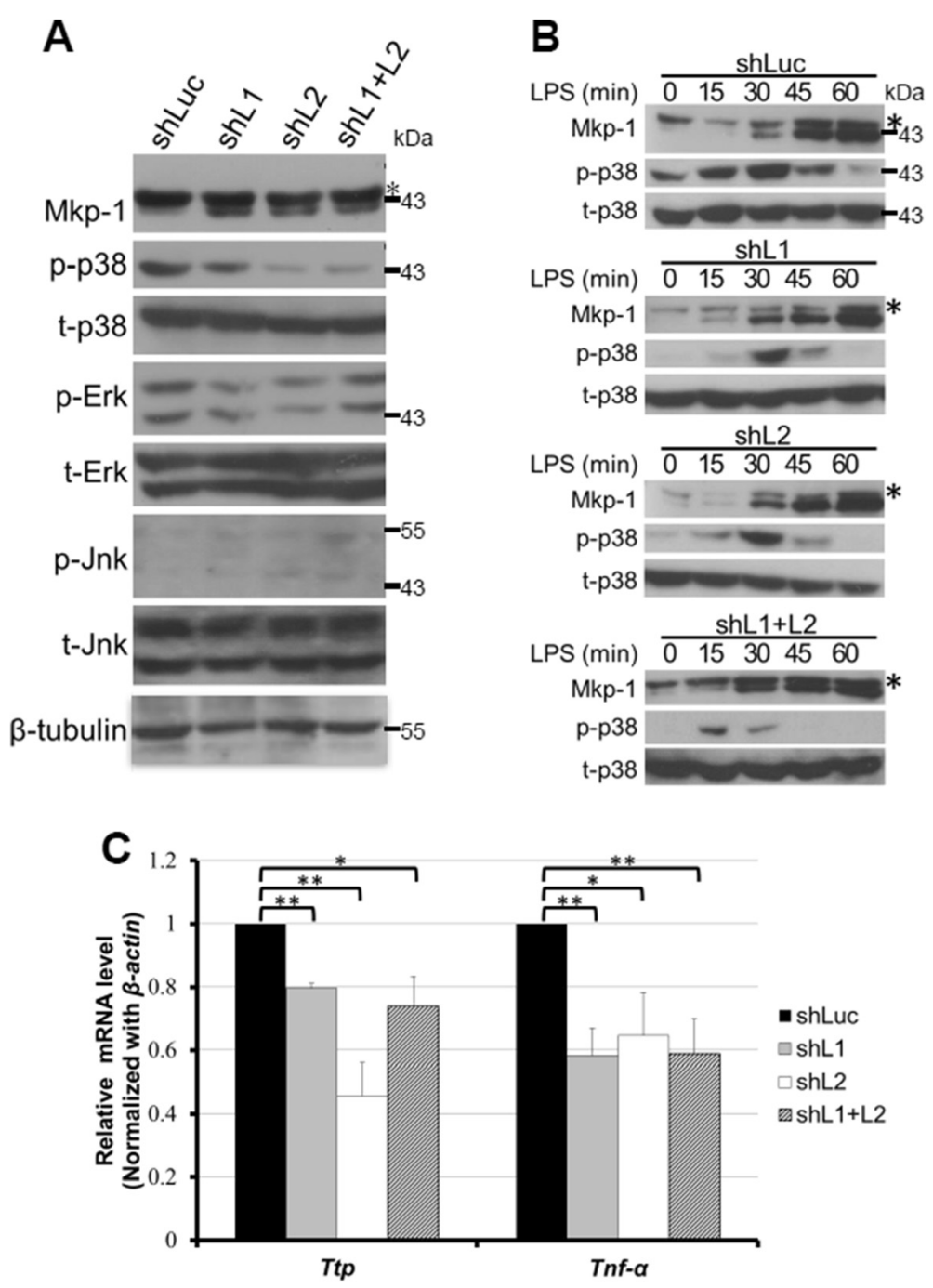

Fig. 6 p38 MAPK activity is regulated by Zfp36l1 and Zfp36l2 through Mkp-1. a Basal activities of three MAPKs in Zfp36l1- and Zfp36l2-knockdown cells. Whole-cell extracts were isolated from RAW264.7 cells with Zfp36l1, Zfp36l2, or Zfp36l1/Zfp36l2 knockdown as indicated. Western blotting was performed to detect MAPKs and phospho-MAPKs. The asterisk indicates cross-reacted Mkp-2. b Mkp-1 expression and p38 activation profiles in different knockdown cells stimulated with LPS for $0,15,30,45$, or 60 min. Whole-cell extracts were collected and separated by SDS-PAGE, and analyzed by western blotting with anti-Mkp-1, anti-p-38, anti-p38, and anti- $\beta$-tubulin antibodies. The asterisk indicates cross-reacted Mkp-2. All of experiments were performed at least three times, and representative data were displayed. c The relative expression levels of Ttp and Tnfa mRNAs in different knockdown cells after LPS stimulation for $15 \mathrm{~min}$. RNA was isolated and performed real-time PCR analysis

3'UTRs, their association with Ttp, and their mRNA expression profiles, which categorized them as immediate-early genes [27, 30]. We found that $M k p-1$ mRNA increased in Zfp36l1-, Zfp3612-, and Zfp3611/Zfp36l2-knockdown cells because of mRNA stabilization (Fig. 3b, c). Tnfo is a wellknown target of TTP family proteins. Much to our surprise, Tnfo mRNA expression decreased in all knockdown cells in the resting state (Fig. 3d). This result may be attributable to the importance of the transcriptional regulation of $\operatorname{Tnf} \alpha$ mRNA controlled by activation of p38 MAPK [47]. Therefore, the increased Mkp-1 expression in Zfp3611- and Zfp36l2-knockdown cells repressed the activity of p38 MAPK (Fig. 6a), which down-regulated Tnfa mRNA expression. Similarly, $\mathrm{Ccl}-2 \mathrm{mRNA}$ expression is also activated by p38 MAPK [48]. This result is consistent with previous reports showing that Mkp-1 overexpression may inactivate Jnk and p38 and thereby inhibit Tnfo and IL-6 expression [39, 49]. However, expression of Ttp and Icam1 mRNA was not significantly different in control and Zfp3611- or Zfp36l2-knockdown cells (Fig. 3d). One possible explanation is that expression of their mRNAs is controlled equally at the transcriptional and posttranscriptional levels $[50,51]$.

The mRNA targets of TTP family proteins are not all the same, although their RNA-binding domains are highly conserved. Ttp-, Zfp3611-, and Zfp3612-knockout 


\section{Normal condition}

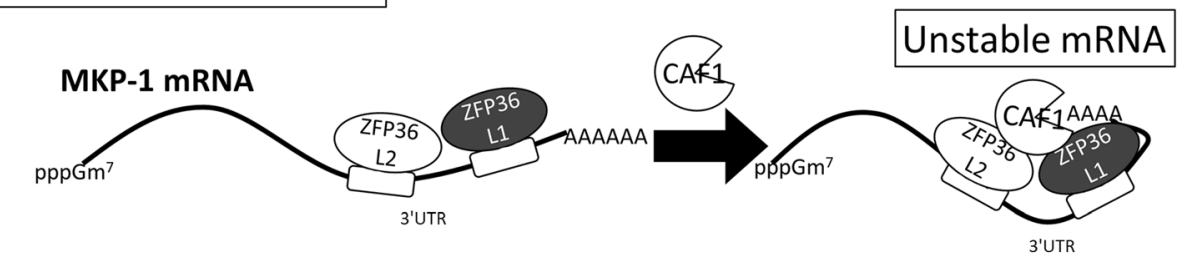

\section{LPS stimulation}

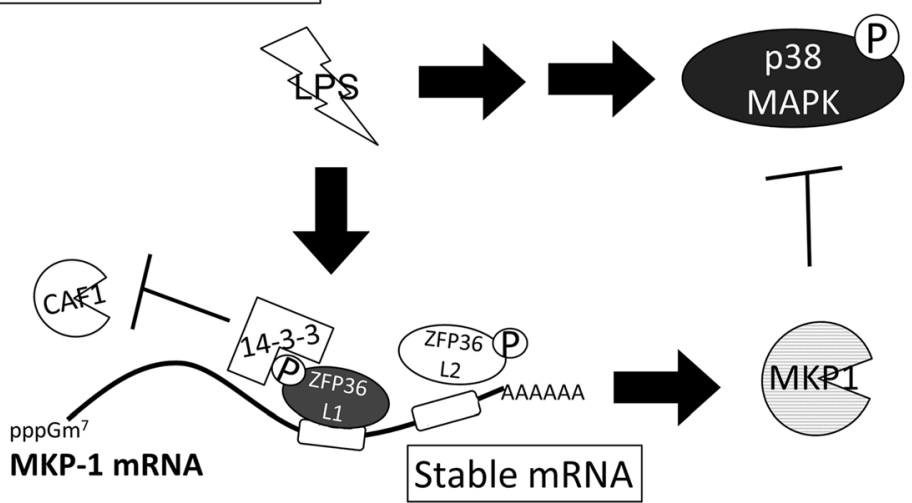

Fig. 7 Hypothesized regulatory networks among Zfp36l1, Zfp36l2, Mkp-1, and p38 MAPK in RAW264.7 cells. Under resting conditions, Zfp36l1 and Zfp36l2 interact with Mkp-1 mRNA 3'UTR and destabilize it, and the cells are sensitive to stimuli such as LPS under low Mkp-1 expression. During early LPS stimulation for 15 min, Zfp36l1 and Zfp36l2 were phosphoprylated and resulted in the decrease of their mRNA destabilization function; so that Mkp-1 mRNA and protein were induced to inactivate LPS-stimulated p38. pppGm: 7-methylguanosine cap. P: phosphate group

mice exhibit different phenotypes. Ttp-sensitive targets identified in knockout cells, such as GM-CSF, polo-likekinase 3, and Ier3, are not regulated in Zfp36l1-knockout cells $[22,25,52]$. On the other hand, ACTH stimulates adrenocortical cells to induce Zfp36l1 and results in downregulation of vegf and star mRNAs [53, 54]. IL-3 mRNA is abnormally stabilized in Zfp36l1-mutated cells [55]. Previously, induced $M k p-1$ mRNA was reported as a Ttp target during the rapid degradation stage after induction $[27,29]$, and also as a Zfp36l1 and Zfp36l2 target in 3 T3L1 preadipocytes [26]. In this study, we demonstrated that Zfp36l1 and Zfp36l2 control $M k p-1$ mRNA expression in the resting stage. Thus, $M k p-1$ mRNA stability might be modulated temporally by Ttp family members in LPSstimulated macrophages. Interestingly, knockdown of either Zfp36l1 or Zfp36l2 affected $M k p-1$ mRNA expression, and no significant additive effect was observed in the double-knockdown cells (Fig. 3b, c). This suggests that there is a functional connection between $\mathrm{Zfp} 36 \mathrm{l} 1$ and Zfp36l2.

Figure 4a shows that the interaction between Zfp3611 and the $M k p-1$ 3'UTR was maintained during LPS stimulation, but the interaction between $\mathrm{Zfp} 36 \mathrm{l} 2$ and the $M k p-1$ 3'UTR was decreased. This may be due to the phosphosphorylation of Zfp3612. Knockdown of Zfp3611 and Zfp36l2 caused the level of $M k p-1$ mRNA highly increased but its stability not increased dramatically in the early stage of LPS stimulation (Fig. 5b, c). It implied that Zfp36l1 and Zfp36l2 might be inactivated in LPSstimulated control cells through phosphorylation. This result confirms that the activation of $M k p-1$ mRNA is regulated by Zfp36l1 and Zfp36l2 after LPS stimulation. Associated proteins may change the functions of Zfp3611 and Zfp3612. Zfp36l1 and Zfp36l2 may also promote the deadenylation of class II ARE-containing mRNAs [20, 56, 57]. After LPS stimulation, however, Zfp3611 may be phosphorylated and form a complex with 14-3-3 (Fig. 4b). This complex may repress Zfp36l1 function and thereby stabilize $M k p-1$ mRNA.

\section{Conclusion}

Expression of proinflammatory mediators is suppressed in resting cells of the innate immune system, whereas it is rapidly induced in response to inflammatory stimulation. These suppression and induction require tight controls to maintain the function of immune system. In addition to transcriptional control, these mediator mRNAs are post-transcriptionally regulated [58]. It has been reported that the ribonuclease regnase-1 brakes $I L-6$ mRNA expression in resting macrophages, and NF$\mathrm{\kappa B}$ signaling would cause phosphorylation and degradation of regnase-1, thereby releasing this brake [59]. As 
shown in Fig. 7, our study suggests that Zfp3611 and Zfp3612 brake $M k p-1$ mRNA expression in resting macrophages for rapid cellular responses to inflammatory stimulation. Upon stimulation, their mRNA levels were decreased and protein was inactivated by phosphorylation to release $M k p-1$ mRNA blocking.

\section{Additional files}

Additional file 1: Figure S1. The potential AREs located in $3^{\prime} U T R$ of Zfp36/1 and Zfp36/2 mRNA from sequence NM 007564 2252-2960 and NM_001001806, respectively. The AREs were underlined.

Additional file 2: Figure S2. The relative expression levels of $I L-1 \beta, I L-6$ and CCI2 mRNAs in different knockdown cells after LPS stimulation for 15 min. RNA was isolated and performed real-time PCR analysis.

\section{Abbreviations}

Ccl2: Chemokine (C-C motif) ligand2; Caf1: Ccr4-associated factor 1; Ccr4: Carbohydrate catabolism repression 4; ERK: Extracellular signal-regulated kinase; GST: Glutathione S-transferase; IL: Interleukin; JNK: c-Jun amino-terminal kinase; LPS: Lipopolysaccharide; MAPK: Mitogen-activated protein kinase; Mkp1: MAPK phosphatase 1; NOT1: Negative on TATA 1; shRNA: Short hairpin RNA; Tnf: Tumor necrosis factor; TTP: Tristetraprolin; Zfp3611: Zinc finger protein 36, C3H type-like 1.

\section{Competing interests}

The authors declare that they have no competing interests.

\section{Authors' contributions}

$\mathrm{KT}$ carried out the knockdown studies, drafted the manuscript. HH verified the knockdown studies. YY and NY carried out the 3'UTR cloning and mRNA half-life analysis. YL and PY participated in figures preparation. SC and GD participated in the antibodies production. CJ conceived of the study, and participated in its design and coordination and helped to draft the manuscript. All authors read and approved the final manuscript.

\section{Acknowledgements}

We thank Yi-Li Liu and I-Ching Huang for technical support with DNA sequencing, supported in part by the Department of Medical Research in National Taiwan University Hospital, and Dr. Sheng-Wei Lin for protein purification support. This work was supported by Academia Sinica, National Taiwan University (10R70602B1 to G. D. Chang) and Ministry of Science and Technology (grant number: NSC 97-2311-B-001-019-MY3 and MOST 103-2311-B-001-023 to C. J. Chang; NSC 99-2314-B-075-008-MY3 and NSC102-2314-B-075-008 to H.H. Wang).

\section{Author details}

${ }^{1}$ Graduate Institute of Biochemical Sciences, College of Life Science, National Taiwan University, No.1 Sec. 4 Roosevelt Road, Taipei 10617, Taiwan. ${ }^{2}$ Department of Pediatrics, Division of Pediatric Immunology and Nephrology, Taipei Veterans General Hospital, No.201, Sec. 2, Shipai Road, Beitou District, Taipei 112, Taiwan. ${ }^{3}$ Department of Pediatrics, Faculty of Medicine, School of Medicine, and Institute of Emergency and Critical Care Medicine, School of Medicine, National Yang-Ming University, No.155, Sec.2, Linong Street, Beitou District, Taipei 112, Taiwan. ${ }^{4}$ Institute of Biological Chemistry, Academia Sinica, No.128, Sec.2, Academia Road, Nankang, Taipei 11529, Taiwan

Received: 21 April 2015 Accepted: 25 June 2015

Published online: 16 July 2015

\section{References}

1. Kyriakis JM, Avruch J. Mammalian MAPK signal transduction pathways activated by stress and inflammation: a 10-year update. Physiol Rev. 2012;92:689-737.
2. Clark AR, Dean JL, Saklatvala J. Post-transcriptional regulation of gene expression by mitogen-activated protein kinase p38. FEBS Lett. 2003;546:37-44.

3. Dean JL, Sully G, Clark AR, Saklatvala J. The involvement of AU-rich element-binding proteins in p38 mitogen-activated protein kinase pathway-mediated mRNA stabilisation. Cell Signal. 2004;16:1113-21.

4. Kracht M, Saklatvala J. Transcriptional and post-transcriptional control of gene expression in inflammation. Cytokine. 2002;20:91-106.

5. Wang $X$, Liu Y. Regulation of innate immune response by MAP kinase phosphatase-1. Cell Signal. 2007;19:1372-82.

6. Sanduja S, Blanco FF, Young LE, Kaza V, Dixon DA. The role of tristetraprolin in cancer and inflammation. Front Biosci. 2012;17:174-88.

7. Slack DN, Seternes OM, Gabrielsen M, Keyse SM. Distinct binding determinants for ERK2/p38alpha and JNK map kinases mediate catalytic activation and substrate selectivity of map kinase phosphatase-1. J Biol Chem. 2001;276:16491-500

8. Hammer M, Mages J, Dietrich H, Servatius A, Howells N, Cato AC, et al. Dual specificity phosphatase 1 (DUSP1) regulates a subset of LPS-induced genes and protects mice from lethal endotoxin shock. J Exp Med. 2006;203:15-20.

9. Chi H, Barry SP, Roth RJ, Wu JJ, Jones EA, Bennett AM, et al. Dynamic regulation of pro- and anti-inflammatory cytokines by MAPK phosphatase 1 (MKP-1) in innate immune responses. Proc Natl Acad Sci U S A. 2006;103:2274-9.

10. Zhao Q, Wang $X$, Nelin LD, Yao Y, Matta R, Manson ME, et al. MAP kinase phosphatase 1 controls innate immune responses and suppresses endotoxic shock. J Exp Med. 2006;203:131-40.

11. Salojin KV, Owusu IB, Millerchip KA, Potter M, Platt KA, Oravecz T. Essential role of MAPK phosphatase-1 in the negative control of innate immune responses. J Immunol. 2006;176:1899-907.

12. Taylor GA, Carballo E, Lee DM, Lai WS, Thompson MJ, Patel DD, et al. A pathogenetic role for TNF alpha in the syndrome of cachexia, arthritis, and autoimmunity resulting from tristetraprolin (TTP) deficiency. Immunity. 1996:4:445-54

13. Carballo E, Lai WS, Blackshear PJ. Feedback inhibition of macrophage tumor necrosis factor-alpha production by tristetraprolin. Science. 1998;281:1001-5.

14. Zubiaga AM, Belasco JG, Greenberg ME. The nonamer UUAUUUAUU is the key AU-rich sequence motif that mediates mRNA degradation. Mol Cell Biol. 1995;15:2219-30.

15. Lai WS, Carballo E, Thorn JM, Kennington EA, Blackshear PJ. Interactions of $\mathrm{CCCH}$ zinc finger proteins with mRNA. Binding of tristetraprolin-related zinc finger proteins to Au-rich elements and destabilization of mRNA. J Biol Chem. 2000;275:17827-37.

16. Rowlett RM, Chrestensen CA, Schroeder MJ, Harp MG, Pelo JW, Shabanowitz $J$, et al. Inhibition of tristetraprolin deadenylation by poly(A) binding protein. Am J Physiol Gastrointest Liver Physiol. 2008;295:G421-430.

17. Gomperts M, Pascall JC, Brown KD. The nucleotide sequence of a CDNA encoding an EGF-inducible gene indicates the existence of a new family of mitogen-induced genes. Oncogene. 1990;5:1081-3.

18. Varnum BC, Ma QF, Chi TH, Fletcher B, Herschman HR. The TIS11 primary response gene is a member of a gene family that encodes proteins with a highly conserved sequence containing an unusual Cys-His repeat. Mol Cell Biol. 1991;11:1754-8.

19. Blackshear PJ, Phillips RS, Ghosh S, Ramos SB, Richfield EK, Lai WS. Zfp36l3, a rodent $X$ chromosome gene encoding a placenta-specific member of the Tristetraprolin family of CCCH tandem zinc finger proteins. Biol Reprod. 2005;73:297-307.

20. Lai WS, Kennington EA, Blackshear PJ. Tristetraprolin and its family members can promote the cell-free deadenylation of AU-rich element-containing mRNAs by poly(A) ribonuclease. Mol Cell Biol. 2003;23:3798-812.

21. Carrick DM, Blackshear PJ. Comparative expression of tristetraprolin (TTP) family member transcripts in normal human tissues and cancer cell lines. Arch Biochem Biophys. 2007;462:278-85.

22. Stumpo DJ, Byrd NA, Phillips RS, Ghosh S, Maronpot RR, Castranio T, et al. Chorioallantoic fusion defects and embryonic lethality resulting from disruption of $\mathrm{Zfp} 36 \mathrm{~L} 1$, a gene encoding a CCCH tandem zinc finger protein of the Tristetraprolin family. Mol Cell Biol. 2004;24:6445-55.

23. Ramos SB, Stumpo DJ, Kennington EA, Phillips RS, Bock CB, Ribeiro-Neto F, et al. The CCCH tandem zinc-finger protein Zfp36l2 is crucial for female fertility and early embryonic development. Development. 2004;131:4883-93.

24. Stumpo DJ, Broxmeyer HE, Ward T, Cooper S, Hangoc G, Chung YJ, et al. Targeted disruption of Zfp36l2, encoding a CCCH tandem zinc finger RNA-binding protein, results in defective hematopoiesis. Blood. 2009;114:2401-10 
25. Chen YL, Huang YL, Lin NY, Chen HC, Chiu WC, Chang CJ. Differential regulation of ARE-mediated TNFalpha and IL-1 beta mRNA stability by lipopolysaccharide in RAW264.7 cells. Biochem Biophys Res Commun. 2006;346:160-8.

26. Lin NY, Lin TY, Yang WH, Wang SC, Wang KT, Su YL, et al. Differential expression and functional analysis of the tristetraprolin family during early differentiation of 3 T3-L1 preadipocytes. Int J Biol Sci. 2012;8:761-77.

27. Lin NY, Lin CT, Chang CJ. Modulation of immediate early gene expression by tristetraprolin in the differentiation of 3 T3-L1 cells. Biochem Biophys Res Commun. 2008:365:69-74.

28. Chen YL, Jiang YW, Su YL, Lee SC, Chang MS, Chang CJ. Transcriptional regulation of tristetraprolin by NF-kappaB signaling in LPS-stimulated macrophages. Mol Biol Rep. 2013;40:2867-77.

29. Emmons J, Townley-Tilson WH, Deleault KM, Skinner SJ, Gross RH, Whitfield ML, et al. Identification of TTP mRNA targets in human dendritic cells reveals TTP as a critical regulator of dendritic cell maturation. RNA. 2008;14:888-902.

30. Hao S, Baltimore D. The stability of mRNA influences the temporal order of the induction of genes encoding inflammatory molecules. Nat Immunol. 2009;10:281-8.

31. Sandler H, Kreth J, Timmers HT, Stoecklin G. Not1 mediates recruitment of the deadenylase Caf1 to mRNAs targeted for degradation by tristetraprolin. Nucleic Acids Res. 2011;39:4373-86.

32. Marchese FP, Aubareda A, Tudor C, Saklatvala J, Clark AR, Dean JL. MAPKAP kinase 2 blocks tristetraprolin-directed mRNA decay by inhibiting CAF1 deadenylase recruitment. J Biol Chem. 2010;285:27590-600.

33. Clement SL, Scheckel C, Stoecklin G, Lykke-Andersen J. Phosphorylation of tristetraprolin by MK2 impairs AU-rich element mRNA decay by preventing deadenylase recruitment. Mol Cell Biol. 2011;31:256-66.

34. Fabian MR, Frank F, Rouya C, Siddiqui N, Lai WS, Karetnikov A, et al. Structural basis for the recruitment of the human CCR4-NOT deadenylase complex by tristetraprolin. Nat Struct Mol Biol. 2013;20:735-9.

35. Blackshear PJ, Perera L. Phylogenetic distribution and evolution of the linked RNA-binding and NOT1-binding domains in the tristetraprolin Family of Tandem CCCH Zinc finger proteins. J Interferon Cytokine Res. 2014;34:297-306.

36. Adachi S, Homoto M, Tanaka R, Hioki Y, Murakami H, Suga H, et al. ZFP36L and ZFP36L2 control LDLR mRNA stability via the ERK-RSK pathway. Nucleic Acids Res. 2014;42:10037-49.

37. Schmidlin M, Lu M, Leuenberger SA, Stoecklin G, Mallaun M, Gross B, et al. The ARE-dependent mRNA-destabilizing activity of BRF1 is regulated by protein kinase B. EMBO J. 2004;23:4760-9.

38. Maitra S, Chou CF, Luber CA, Lee KY, Mann M, Chen CY. The AU-rich element mRNA decay-promoting activity of BRF1 is regulated by mitogen-activated protein kinase-activated protein kinase 2. RNA. 2008;14:950-9.

39. Chen P, Li J, Barnes J, Kokkonen GC, Lee JC, Liu Y. Restraint of proinflammatory cytokine biosynthesis by mitogen-activated protein kinase phosphatase-1 in lipopolysaccharide-stimulated macrophages. J Immunol. 2002;169:6408-16.

40. Brooks SA, Blackshear PJ. Tristetraprolin (TTP): interactions with mRNA and proteins, and current thoughts on mechanisms of action. Biochim Biophys Acta. 1829;2013:666-79.

41. Liang J, Song W, Tromp G, Kolattukudy PE, Fu M. Genome-wide survey and expression profiling of CCCH-zinc finger family reveals a functional module in macrophage activation. PLoS One. 2008;3:e2880.

42. Cao H, Urban Jr JF, Anderson RA. Cinnamon polyphenol extract affects immune responses by regulating anti- and proinflammatory and glucose transporter gene expression in mouse macrophages. J Nutr. 2008;138:833-40.

43. Martinez-Pastor M, Vergara SV, Puig S, Thiele DJ. Negative feedback regulation of the yeast $\mathrm{CTH} 1$ and $\mathrm{CTH} 2$ mRNA binding proteins is required for adaptation to iron deficiency and iron supplementation. Mol Cell Biol. 2013;33:2178-87.

44. Brook M, Tchen CR, Santalucia T, Mcllrath J, Arthur JS, Saklatvala J, et al. Posttranslational regulation of tristetraprolin subcellular localization and protein stability by p38 mitogen-activated protein kinase and extracellular signal-regulated kinase pathways. Mol Cell Biol. 2006;26:2408-18.

45. Hitti E, lakovleva T, Brook M, Deppenmeier S, Gruber AD, Radzioch D, et al. Mitogen-activated protein kinase-activated protein kinase 2 regulates tumor necrosis factor mRNA stability and translation mainly by altering tristetraprolin expression, stability, and binding to adenine/uridine-rich element. Mol Cell Biol. 2006;26:2399-407.
46. Ramos SB. Characterization of DeltaN-Zfp36l2 mutant associated with arrest of early embryonic development and female infertility. J Biol Chem. 2012;287:13116-27.

47. Campbell J, Ciesielski CJ, Hunt AE, Horwood NJ, Beech JT, Hayes LA, et al. A novel mechanism for TNF-alpha regulation by p38 MAPK: involvement of NF-kappa B with implications for therapy in rheumatoid arthritis. J Immunol. 2004;173:6928-37.

48. Marra F, Delogu W, Petrai I, Pastacaldi S, Bonacchi A, Efsen E, et al. Differential requirement of members of the MAPK family for CCL2 expression by hepatic stellate cells. Am J Physiol Gastrointest Liver Physiol. 2004:287:G18-26.

49. Shepherd EG, Zhao Q, Welty SE, Hansen TN, Smith CV, Liu Y. The function of mitogen-activated protein kinase phosphatase-1 in peptidoglycan-stimulated macrophages. J Biol Chem. 2004;279:54023-31.

50. Tchen CR, Brook M, Saklatvala J, Clark AR. The stability of tristetraprolin mRNA is regulated by mitogen-activated protein kinase p38 and by tristetraprolin itself. J Biol Chem. 2004:279:32393-400.

51. Mahtani KR, Brook M, Dean JL, Sully G, Saklatvala J, Clark AR. Mitogen-activated protein kinase p38 controls the expression and posttranslational modification of tristetraprolin, a regulator of tumor necrosis factor alpha mRNA stability. Mol Cell Biol. 2001;21:6461-9.

52. Horner TJ, Lai WS, Stumpo DJ, Blackshear PJ. Stimulation of polo-like kinase 3 mRNA decay by tristetraprolin. Mol Cell Biol. 2009;29:1999-2010.

53. Ciais D, Cherradi N, Bailly S, Grenier E, Berra E, Pouyssegur J, et al. Destabilization of vascular endothelial growth factor mRNA by the zinc-finger protein TIS11b. Oncogene. 2004;23:8673-80.

54. Duan H, Cherradi N, Feige JJ, Jefcoate C. CAMP-dependent posttranscriptional regulation of steroidogenic acute regulatory (STAR) protein by the zinc finger protein ZFP36L1/TIS11b. Mol Endocrinol. 2009;23:497-509.

55. Stoecklin G, Colombi M, Raineri I, Leuenberger S, Mallaun M, Schmidlin M, et al. Functional cloning of BRF1, a regulator of ARE-dependent mRNA turnover. EMBO J. 2002;21:4709-18.

56. Lai WS, Blackshear PJ. Interactions of $\mathrm{CCCH}$ zinc finger proteins with $\mathrm{mRNA}$ : tristetraprolin-mediated AU-rich element-dependent mRNA degradation can occur in the absence of a poly(A) tail. J Biol Chem. 2001;276:23144-54.

57. Lai WS, Kennington EA, Blackshear PJ. Interactions of CCCH zinc finger proteins with mRNA: non-binding tristetraprolin mutants exert an inhibitory effect on degradation of AU-rich element-containing mRNAs. J Biol Chem. 2002;277:9606-13.

58. Ivanov P, Anderson P. Post-transcriptional regulatory networks in immunity. Immunol Rev. 2013;253:253-72.

59. Iwasaki H, Takeuchi O, Teraguchi S, Matsushita K, Uehata T, Kuniyoshi K, et al. The IkappaB kinase complex regulates the stability of cytokine-encoding mRNA induced by TLR-IL-1R by controlling degradation of regnase-1. Nat Immunol. 2011;12:1167-75.

\section{Submit your next manuscript to BioMed Central and take full advantage of:}

- Convenient online submission

- Thorough peer review

- No space constraints or color figure charges

- Immediate publication on acceptance

- Inclusion in PubMed, CAS, Scopus and Google Scholar

- Research which is freely available for redistribution 